\title{
Correction to: COVID-19 vaccine preferences among university students in Hong Kong: a discrete choice experiment
}

\author{
Xue $\mathrm{Li}^{1,2^{*}}$ (D), Man Yui Chong ${ }^{3}$, Ching Yui Chan ${ }^{3}$, Vindy Wing Sum Chan ${ }^{3}$ and Xinning Tong ${ }^{1}$
}

\section{Correction to: BMC Research Notes (2021) 14:421} https://doi.org/10.1186/s13104-021-05841-z

Following publication of the original article [1], the authors identified an error in the author name of Vindy Wing Sum Chan.

The incorrect author name is: Vindy Wing Sun Chan.

The correct author name is: Vindy Wing Sum Chan.

The author group has been updated above and the original article [1] has been corrected.

\section{Author details}

'Department of Medicine, Li Ka Shing Faculty of Medicine, The University of Hong Kong, Hong Kong, People's Republic of China. ${ }^{2}$ Centre for Safe Medication Practice and Research, Department of Pharmacology and Pharmacy, L Ka Shing Faculty of Medicine, The University of Hong Kong, Hong Kong, People's Republic of China. ${ }^{3}$ Li Ka Shing, Faculty of Medicine, University of Hong Kong, Hong Kong, People's Republic of China.

Published online: 31 December 2021

\section{Reference}

1. LiX, Chong MY, Chan CY, Chan VW, Tong X. COVID-19 vaccine preferences among university students in Hong Kong: a discrete choice experiment. BMC Res Notes. 2021;14:421. https://doi.org/10.1186/ s13104-021-05841-z.

\section{Publisher's Note}

Springer Nature remains neutral with regard to jurisdictional claims in published maps and institutional affiliations. 